\title{
"Não me lembro, não me recordo..." Experiências com cultura visual antes da Graduação em Pedagogia.
}

"I do not remember, I do not remember ..." Experiences with visual culture before Graduation in Pedagogy.

Nathalye Nallon Machadoi, Anderson Ferrari ii

\section{Resumo}

O presente artigo é resultado de um segundo movimento de uma pesquisa que buscava inicialmente compreender a relação de alunos e alunas da Educação Básica com a cultura visual, principalmente por meio de suas produções imagéticas. No segundo momento, a pesquisa foi realizada com estudantes de Pedagogia de uma Universidade Federal e teve como objetivo compreender suas relações com a cultura visual antes de ingressarem na graduação. As alunas responderam questionários qualitativos, e nesse universo, selecionamos as questões que diziam do trabalho dos professores de História dos Ensinos Fundamental e Médio com os artefatos culturais. Esta análise nos possibilitou refletir acerca de questões importantes, indicando que as imagens vêm sendo trabalhadas na forma de ilustração e muito pouco como produção.

Palavras-chave: Cultura visual, graduação, Pedagogia.

\section{ABSTRACT}

This paper stems from a second phase of a research which at first searched to understand the relationship established between male and female students from Basic Education level and visual culture mainly through their imagistic productions. Then, as a second step, the research was carried out among undergraduate students enrolled in Pedagogy courses from a Federal University aiming to understand their relations to visual culture before starting graduate studies. Female students answered qualitative questionnaires and from this sample it was selected those questions approaching some works with cultural artifacts applied by History teachers from primary and secondary education. This analysis made it possible to reflect on relevant issues pointing out that images have been worked as an illustration and much less as a production.

Revista Digital do LAV - Santa Maria - vol. 10, n. 1, p. 82 - 98 - jan./abril. 2017 ISSN 19837348

http://dx.doi.org/10.5902/1983734826286 
Keywords: Visual culture, graduation, Pedagogy.

A cultura visual é um campo de conhecimento recente e, portanto, em disputa e em expansão. Refere-se a diversos temas relacionados com a arte, a televisão, a publicidade, o cinema, a fotografia, a educação, enfim, com os processos educativos que dizem da construção de imagens e do que chamamos de realidade. Imagens e realidades que também nos constituem. Esses processos também ocorrem no interior das escolas, envolvendo os professores, os alunos e a cultura escolar, formando hábitos, elegendo o que se deve e o que não se deve ensinar (FORQUIN, 1993 e 2001). Os processos culturais, entendidos como valores, traduzem escolhas. Escolhas estas que refletem interesses, ideologias e hábitos. O trabalho com as imagens no cotidiano escolar não acontece de forma distinta. Os currículos escolares são construídos considerando tais elementos, elegendo, acrescentando, suprimindo, escolhendo...

No contexto educacional que abrange ensino e pesquisa, essas questões tomaram força a partir da necessidade de dar atenção para a fluidez e provisoriedade das imagens no cotidiano, nas relações de ensino-aprendizagem e nos sentidos produzidos pelos estudantes e pelas estudantes. Dessa forma, podemos dizer que os estudos da cultura visual não se restringem à organização de uma disciplina, mas dizem de um conjunto de ações e práticas educativas que buscam analisar as variadas maneiras de produção, usos e entendimentos dos artefatos culturais e visuais, ou seja, como olhamos para essas imagens e como elas nos olham.

Nesse cenário de interesse pela discussão da cultura visual, podemos destacar autores como Fernando Hernández (2010), José Luiz Brea (2005) e John Walter \& Sarah Chaplin (2002), que articulam o nascimento e a expansão desse campo com as artes e com a educação, ressaltando o enfoque interdisciplinar que marca essa atenção nas imagens, nos artefatos culturais e suas vinculações com os processos de subjetivação. Autores que concordam que a cultura visual designa um objeto teórico problemático, visto que não se trata de um movimento político e tampouco acadêmico. Ela é o trabalho com as visualidades e, diferentemente dos estudos de gênero, raça ou classe, os estudos de cultura visual não comportam um componente político específico. No entanto, a cultura visual se aproxima da linguagem, podendo ambas serem consideradas como meios nos 
"Não me lembro, não me recordo..." Experiências com cultura visual antes da Graduação em Pedagogia.

quais se projeta o político. No Brasil, essa discussão tomou força a partir dos estudos de Marilda de Oliveira (2012), Raimundo Martins (2009) e Ana Mae Barbosa (2013) que ampliaram as análises tomando a realidade brasileira como campo de investigação para pensar práticas diferentes que nos ajudam a colocar sob interrogação os sentidos da educação, das artes e da cultura.

É pertinente afirmar que, nas escolas e, também, nos cursos de graduação, a cultura visual se faz presente de forma bastante corriqueira. Assim, a graduação em Pedagogia está diretamente implicada nessa expansão dos estudos da cultura visual, visto que cada vez mais as imagens compõem o universo das salas de aula, seja na graduação ou nos Ensinos Fundamental e Médio. A graduação, especialmente os cursos de formação de professores, é o momento de problematizar e colocar sob suspeita o que está dado, naturalizado. Trabalhar com essa perspectiva de problematização é dar valor às experiências com cultura visual, por mais comuns que elas sejam, investindo na transformação do ordinário em extraordinário. Fernando Hernández (2007) nos convida a pensar como as relações com a cultura visual produzem olhares sobre o mundo, sobre nós mesmos e sobre os outros.

Com essas inquietações como foco, passamos a buscar contatos com as escolas na cidade de Juiz de Fora para verificar as relações entre essa sociedade imagética, os estudos da cultura visual, os processos de ensino-aprendizagem e os modos de subjetivação que estão sendo construídos nesse contexto escolar. Em um primeiro movimento de pesquisa (2012-2013), trabalhamos com as produções de imagens entre alunos e alunas no contexto de quatro escolas (pública municipal, pública estadual, pública federal e particular). Produções que foram ou não solicitadas pelos professores e professoras. Nas falas dos participantes, a escola e a ação dos professores e professoras na solicitação de trabalhos com imagens apareciam raramente, eles e elas não reconheciam o trabalho com as imagens nas práticas educativas cotidianas.

No entanto, também diziam de uma produção cotidiana e espontânea de imagens (via celulares) como parte da realidade escolar, como organizadoras das relações interpessoais. Portanto, a pesquisa nos sugeriu um desafio para as escolas, para as universidades e para as/os professoras/es, que passa pela formação docente e o currículo, entendendo que a sociedade imagética nos instiga a um trabalho com a cultura visual como um campo de saber e poder, de produção de sujeitos. Os alunos e alunas 
que estão nas universidades trazem, para a formação docente, algum tipo de trabalho com a cultura visual, alguma experiência com a problematização das imagens?

Em um segundo movimento de pesquisa (2014-2015) nos dedicamos ao trabalho de investigação junto aos graduandos e graduandas dos cursos de Licenciatura em História e de Pedagogia. Nosso interesse passava pela seguinte questão de pesquisa: que relações com as imagens estas alunas e estes alunos traziam para a graduação e quais experiências conseguiam identificar como formativas nos seus cursos de licenciatura? A articulação se dava, então, entre a formação docente, cultura visual, currículo, nas suas diferentes relações com as imagens e o saber, sejam elas voltadas para o conhecimento científico ou aquelas que estão direcionadas à leitura, à elaboração, ao entendimento e à relação com as imagens. A partir dessa formação, também nos interessava pensar: - Que desafios e potencialidades estas graduandas e graduandos identificavam para o trabalho com as imagens?

Para este artigo, trabalharemos com as respostas das alunas ${ }^{1}$ do curso de Pedagogia ao questionário qualitativo e como elas percebiam o trabalho com as imagens antes da graduação, principalmente na disciplina de História. Uma disciplina que trabalha com as imagens o tempo todo, visto que a ação do ensino de História pode ser traduzida na intenção de levar os alunos e alunas a produzirem imagens de um tempo que não viveram. A coleta de dados se deu na turma de sétimo período do curso, por meio de questões abertas que giravam em torno da formação antes da graduação e de questões sobre a formação na graduação. Nesse universo, selecionamos as questões que diziam do trabalho dos professores de História dos Ensinos Fundamental e Médio com os artefatos culturais. Estamos lidando com a cultura visual, com o currículo, com a formação docente e com os modos de subjetivação em uma perspectiva pósestruturalista, que significa dizer que nossas abordagens e foco de análise tomam a centralidade da linguagem na organização e como lócus de produção das relações que a cultura estabelece entre saber, sujeito, conhecimento e poder.

\section{A cultura visual como potencialidade no espaço educativo}

\footnotetext{
${ }^{1}$ Por ser um curso cuja predominância é feminina, faremos a opção por utilizarmos alunas para nos referirmos aos participantes da pesquisa.
}

Revista Digital do LAV - Santa Maria - vol. 10, n. 1, p. 82 - 98 - jan./abril. 2017 ISSN 19837348

http://dx.doi.org/10.5902/1983734826286 
"Não me lembro, não me recordo..." Experiências com cultura visual antes da Graduação em Pedagogia.

A escola, assim como todos os espaços da nossa sociedade, é povoada de imagens das mais diferentes vertentes. São imagens dos alunos e alunas, produzidas e compartilhadas, são imagens institucionais e didáticas, usadas como suporte de aprendizagem, são imagens da mídia, da internet, ou seja, a escola é um ambiente de cuja rotina as imagens fazem parte. Especificamente no caso da pesquisa com a qual nos ocupamos agora, interessa-nos discutir as formas como as alunas do curso de Pedagogia fazem a reflexão acerca de suas experiências com imagens antes de se tornarem graduandas. Experiências que trazem à tona as escolas. Como nos lembram Tourinho et alii (2013), é extremamente importante, em uma sociedade como a nossa, atravessada por artefatos de produção de imagens, que as escolas e suas propostas educacionais se preocupem com a formação de sujeitos mais sensíveis à presença das imagens nos nossos cotidianos. Uma preocupação que deve estar nas escolas, mas que antecede a entrada, como profissionais, dos professores e professoras nesse espaço de produção de sujeitos, implicando a relação entre formação docente, práticas escolares, conhecimentos, currículos e escolas.

Trabalhar com as experiências que trazem das escolas, antes da graduação, significa trabalhar com a relação entre experiência, memória, narrativas e, por meio dessas relações que colocam em vigor os processos de rememoração, fazer as graduandas de Pedagogia atribuírem significado e valor ao que viveram. Segundo Nóvoa (1995), os professores e professoras, vistos individualmente, constroem seus conhecimentos e saberes a partir das memórias individuais que são capazes de conferir sentidos às suas práticas e repertórios. Essas memórias e experiências são trazidas para a graduação, de maneira que esse momento de formação se constitui como espaço de produção e ressignificação de saberes. O que aprenderam na escola, seja como conteúdo ou como aquilo que se constitui como um fazer docente, faz parte das futuras professoras e também professores, são lembranças trazidas para a formação a qual, ao não dar lugar a isso, perde a oportunidade de problematizar esse momento de formação. As imagens fazem parte do cotidiano escolar e da constituição dessas alunas que chegam à Pedagogia. Dialogando com Nóvoa, a partir do trabalho de Tardif (2002), somos convidados a pensar que os saberes dos professores e professoras parecem estar embasados em relações constantes entre o que eles e elas pensam que são (imagens que constroem de si, emoções, experiências, expectativas com o curso, história pessoal) e o que eles e elas fazem nesse contexto específico de formação que é a graduação na Pedagogia.

Revista Digital do LAV - Santa Maria - vol. 10, n. 1, p. 82 - 98 - jan./abril. 2017 ISSN 19837348 http://dx.doi.org/10.5902/1983734826286 
As imagens extrapolam a função apenas de ilustrar, entendendo-se que por elas e através delas nos educamos e produzimos conhecimento. Essa característica atribuída às imagens, de formação e produção de conhecimento em detrimento de sua função ilustrativa, é algo relativamente recente em nossas escolas. As imagens educam nosso olhar, "aquilo que vemos", de maneira que as práticas de ver são construídas social e culturalmente. $\mathrm{O}$ trabalho com a cultura visual diz desses impactos e implicações dessas experiências de ver e ser visto nos nossos dias. Na escola, frequentemente, as imagens "serviam" para mostrar algo a que provavelmente os estudantes ainda não haviam tido acesso: imagens de batalhas, figuras históricas, paisagens, entre outras, que de certa maneira faziam parte do cotidiano escolar, principalmente por meio dos livros didáticos. Problematizar as práticas escolares que se tornaram corriqueiras, também se configura como uma das funções da cultura visual.

Dessa maneira, tanto as práticas de ensino que estavam em circulação nessa relação com as imagens, quanto as imagens em si podem ser entendidas como discursos e, portanto, como espaços de investigação e de questionamentos, distanciando-se assim de uma definição como coleção de textos escritos e visuais. Esta parece ser uma posição política do trabalho com as imagens que coloca, no centro do debate da educação, as questões da subjetividade, ou seja, "quem é o que vê" (HERNÁNDEZ, 2007). Trabalhar educação com a cultura visual a partir das imagens é colocar em evidência algumas questões de subjetividade: quem vê e o que vemos?

$\mathrm{Na}$ pesquisa com a qual dialogamos, pudemos perceber, por meio das falas das participantes, que suas experiências escolares com imagens se basearam bastante na relação entre conteúdo e ilustração. Quando dizemos conteúdo e ilustração, estamos nos referindo ao fato de que as imagens foram utilizadas como suporte ilustrativo ao conteúdo programático que estava sendo ministrado. Consideramos pertinente trazer, aqui, fragmentos das falas de alunas da graduação em Pedagogia, em relação às suas experiências com o trabalho com imagens em sua trajetória escolar:

Não tenho lembrança do ensino de História no Ensino Fundamental 1, mas no $8^{\circ}$ e $9^{\circ}$ anos e no Ensino Médio tive professores que me despertaram interesse e o gosto pela História, principalmente da História do Brasil. Em relação ao trabalho com imagens, na maior parte os professores usavam imagens apenas como ilustração e não davam grande importância. (Questionário 11). 
Todos exerceram uma metodologia tradicional, ou seja, explanação da temática tendo como suporte o livro didático, seguida de exercícios em sua maioria com perguntas e respostas baseadas no texto do livro didático. As imagens exploradas eram as contidas nos livros didáticos, não me recordo de ter havido exploração de materiais como filmes, charges, fotografias. Foram ressaltadas obras de arte no contexto do Renascimento. (Questionário 24).

O caráter ilustrativo da imagem pode ser entendido mais como suporte e menos como produção. Assim, ao relacionar um tema à sua imagem de maneira passiva, a escola parece desconsiderar o fato de que não existe passividade diante de uma imagem. Fernando Hernández (2000) sugere que existam intérpretes e construtores, pois há uma estreita ligação entre o que se vê com as experiências vividas por quem vê. As imagens estão diretamente implicadas no ensino de História, visto que o trabalho com a construção dos conhecimentos históricos diz da articulação das imagens a partir dos suportes utilizados em sala de aula, seja o livro didático que já traz as imagens, ou o trabalho com obras de arte, charges, fotografias, documentários, ou mesmo a aula expositiva em que o professor e a professora vão construindo imageticamente o que vão falando. Historiadores de maneira geral entendem que a construção do conhecimento histórico é complexa, envolvendo diversas discussões e, sobretudo, servindo para problematizações que o trabalho com as fontes, os discursos, as imagens exige. (JENKINS, 2011).

Mesmo com a entrada de diversos recursos didáticos para o ensino de História no Brasil, principalmente a partir da década de 1980, com a televisão e o vídeo, o trabalho do professor e professora de História consiste em reunir os fragmentos dispersos e selecionados, dando-Ihes certa forma e sentido para os alunos e alunas. Assim, vão construindo uma trama e narrativa do passado a partir desses recursos que selecionam, que são marcados pelas experiências que viveram e por suas subjetividades. Essas futuras professoras trazem essas marcas do professor - no Ensino Médio tive professores que me despertaram interesse e o gosto pela História, principalmente da História do 
Brasil. Consideram a "marca" do professor, mas não reconhecem o trabalho limitado com as imagens, que se restringiam ao seu uso como "ilustração".

Podemos pensar que o trabalho com a educação da cultura visual atravessa a História, visando um olhar crítico, curioso e problematizador em relação às imagens e aos modos de ver. Trabalhar com a História e com todas as formas de ensinar e aprender como problematização é dar lugar ao conhecimento como algo construído e não "dado" ou "natural". É dar um passo atrás para transformar em "problema de investigação" aquilo que tomamos como natural, é uma forma de se desprender de si mesmo para colocar sob suspeita as formas de pensar e agir (MARSHALL, 2008). A imaginação, o prazer e a crítica são partes integrantes do trabalho com as imagens, com a produção e interpretação das visualidades. As imagens constroem um "nós" e os "outros", elas falam de nós e dos outros, elas contam de nós para os outros, dos outros para nós, enfim, elas intercambiam nossos encontros e novas possibilidades de ser e estar no mundo.

Convidar as alunas a olharem para as formas de utilização das imagens na escola é também um convite a pensar outras maneiras dessa inserção e exploração da cultura visual como possibilidades educativas de um amplo espectro de visualidades que inclua imagens advindas das artes, da fotografia, da publicidade, do cinema e, também dos livros didáticos, de maneira crítica. Um trabalho de formação e fortalecimento das futuras professoras e alunas da Pedagogia para manusearem diferentes artefatos culturais, ampliando o olhar pedagógico e educativo sobre as imagens. Os livros didáticos aparecem com força quando se fala da presença de imagens na escola. Ele parece ser o lugar de excelência das imagens, muito embora, sem a identificação de um trabalho crítico e criativo dessas imagens e tampouco desse material didático: Todos exerceram uma metodologia tradicional, ou seja, explanação da temática tendo como suporte o livro didático. Minimamente podemos dizer que a proposta da pesquisa serviu, de certa forma, para nomear essa prática de utilização das imagens como "ilustração" no campo da metodologia tradicional. Dessa maneira, a graduação, ao colocar sob interrogação as experiências, as memórias e as narrativas que acionam quando falam do período de Ensino Médio, pode se transformar em um espaço-tempo que aguce a interpretação, a negociação e a crítica com o tipo de educação que tiveram e o tipo que querem colocar em vigor quando voltarem às escolas.

Rever a própria trajetória escolar, no transcorrer do processo formativo inicial da graduação, pode significar uma possibilidade de estranhamento às práticas tão 
"Não me lembro, não me recordo..." Experiências com cultura visual antes da Graduação em Pedagogia.

naturalizadas. Pode proporcionar, também, uma análise aprofundada do que, de fato, foi importante naquele contexto de aprendizagem.

Revisitar as práticas da Educação Básica pelas quais passaram proporcionou às alunas da Pedagogia uma possível ressignificação de sentidos e experiências. Por meio desse exercício, despertado pelo instrumento de pesquisa, foi possível dizer muitas coisas. E elas disseram. Não somente disseram de uma ausência do trabalho com outras formas de imagens que povoam o nosso cotidiano e nossas escolas - As imagens exploradas eram as contidas nos livros didáticos, não me recordo de ter havido exploração de materiais como filmes, charges, fotografias - mas também afirmaram o lugar dessas produções que ocuparam as suas vivências diárias como alunos e alunas. O que as falas das alunas da Pedagogia nos trazem é uma vinculação das imagens como artefatos que articulam informação, conhecimento, entretenimento e comunicação.

\section{"Não me lembro, não me recordo..." Experiências com cultura visual antes da Graduação em Pedagogia}

As falas das alunas nos colocam diante da importância de entendermos o espaço escolar como um lugar em que as imagens podem tomar sentidos que extrapolam conteúdos programáticos. Quando o título deste texto foi surgindo, a partir das muitas repetições da expressão "não me lembro, não me recordo", foi inevitável perceber, por meio das respostas dadas pelas participantes, que o trabalho com imagens não foi significativo o bastante para recordações expressivas. A relação com as imagens, quando destacada de forma relevante, vinha vinculada a uma avaliação também relevante das práticas adotadas pelos professores. Dois pontos nos questionam: em que sentido estão considerando o trabalho com as imagens - apenas no uso do audiovisual, ou seja, que sentido de imagem estão acionando? Outro diz do reconhecimento do trabalho apenas como aquele utilizado na relação ensino-aprendizagem e exigido pelos professores e professoras. Essas são questões que merecem nossa atenção, uma vez que a cultura visual diz do trabalho com imagens não somente como conhecimento, mas como comunicação e entretenimento. Assim, podemos pensar que o trabalho dos professores e professoras com imagem é um trabalho cotidiano e diz da ação nas salas de aula.

Imagens influenciam, direcionam, constroem e desconstroem sentidos e significados de experiências de alunos e alunas, de professores e professoras. Elas desenham nossas

Revista Digital do LAV - Santa Maria - vol. 10, n. 1, p. 82 - 98 - jan./abril. 2017 ISSN 19837348

http://dx.doi.org/10.5902/1983734826286 
possibilidades de ser e estar no mundo, de pensar e agir, de maneira que as imagens nos formam, construindo e organizando traços identitários que nos representam. Assim, as imagens presentes ou ausentes nas escolas afetam formas de socialização, dizem de seleção que constroem os currículos e os sujeitos (SILVA, 1999).

Trabalhar com o universo de 40 alunas do curso de Pedagogia representa a possibilidade de colocar em evidência a diversidade de escolas e de experiências escolares que constituem essa turma. E, como são alunas ainda em processo de formação na universidade, suas experiências com o Ensino Médio são bastante recentes, o que nos diz, também, sobre práticas que aconteceram em datas não muito distantes... Olhar para o ensino de História que vivenciaram nos Ensinos Fundamental e Médio é dar lugar a essa diversidade que constitui a sociedade brasileira, que está nas escolas e seus modelos de ensino de História, ressaltando, em última instância, essa diversidade na formação docente e entendimento do ensino de História. Assim, da mesma forma em que aparecem alunas que não identificam o trabalho com as imagens além do modelo tradicional, existem outras alunas que nos brindam com lembranças mais positivas do uso das imagens.

Foram excelentes professores que trouxeram a História de maneira interessante, devo minha boa relação com a História a eles; no seu trabalho levavam bastante filmes e documentários. (Questionário 15).

No Ensino Fundamental trabalhei muito com a parte de 'decoreba"(sic). Só fui realmente aprender História e gostar de História no Ensino Médio, onde tive um estudo bem amplo e dinâmico. O trabalho dos professores com imagens no Ensino Médio foi totalmente diferenciado... Filmes, charges, fotografias e documentários não faltaram no Ensino Médio. Mesmo que o professor não pudesse passar na sala, sempre recomendava algum tipo de filme. (Questionário 4).

"História de maneira interessante", "gosto pela História a partir do trabalho amplo e dinâmico", "variedade e diversidade de artefatos culturais" são algumas das constatações presentes nas falas acima e que demonstram o trabalho com as imagens a partir do seu poder de sedução e força pedagógica, na medida em que a relação de ensino- 
"Não me lembro, não me recordo..." Experiências com cultura visual antes da Graduação em Pedagogia.

aprendizagem parece passar pelo despertar dos interesses. As falas também denunciam que nem todas olham a mesma coisa quando são convidadas a pensar suas experiências com as imagens nos Ensinos Fundamental e Médio. Essa força polissêmica das lembranças e esquecimentos também é uma característica do trabalho com as imagens, o que desafia as escolas e as professoras a refletirem sobre como vemos e por que vemos de determinadas maneiras. As lembranças, as experiências e as imagens fazem circular os diferentes sentidos e valores que nos constituem, que são gerados na interação com os sujeitos.

O que nos desafia, ainda hoje, no trabalho com imagens na escola, é a excessiva "didatização" (se é que podemos chamar assim a busca incansável pela didática...) do que se vê. É a procura incessante por sentido e adequação aos conteúdos, pois fora isso como a escola se apresentaria? Como sua função na sociedade se justificaria? As amarras desses excessos são sentidas nas falas das alunas em suas reflexões sobre a escola que as formou sob a forma de esquecimentos e falta de relevância. Assim:

Não aprendi muita coisa não. Lembro somente do ensino de Grécia e Roma e mais nada. Eles mesmos [os professores] ao passarem o conteúdo, mostravam certo desinteresse. (Questionário 3).

O trabalho pedagógico com as imagens exige tempo e habilidade, sob o risco de se tornar "decorativo". Mais do que isso, trabalhar com imagens pressupõe uma formação capaz de acionar uma avaliação do que será trabalho envolvendo seleção das imagens e interpretação sobre que sentidos serão trabalhados. Assim, este trabalho diz da transformação de formas de aprender e ensinar, o que nem sempre é encarado com interesse pelos professores formados em outros contextos em que o trabalho com as imagens não fez parte. Por isso, pensar o trabalho que vivenciaram enquanto estudantes do Ensino Médio nos parece importante para colocar em discussão os modos de ensinar e aprender que querem colocar em vigor ao saírem da universidade, as formas que a sociedade vai se constituindo em meio à proliferação de formas de registros imagéticos que atingem a todos e todas e que instituem formas diversas de interação com as imagens que organizam o cotidiano escolar. Nesse caminho, uma reflexão feita por Ana Mae Barbosa vem ao encontro de nossos questionamentos.

A educação deveria prestar atenção ao discurso visual. Ensinar a gramática visual e sua sintaxe através da arte é tornar as crianças conscientes da produção humana de alta qualidade é uma forma

Revista Digital do LAV - Santa Maria - vol. 10, n. 1, p. 82 - 98 - jan./abril. 2017 ISSN 19837348

http://dx.doi.org/10.5902/1983734826286 
de prepara-las para compreender e avaliar todo o tipo de imagem. (BARBOSA, 1998, p. 17).

Quando acreditamos na escola enquanto espaço de potencialidades para o trabalho com imagens, estamos levando em consideração falas significativas que obtivemos por meio da pesquisa. Para além dessas falas que nos mobilizam, nosso interesse também busca colocar em circulação uma questão que nos parece importante para as escolas e para os jovens hoje em dia: por que nós, professores e professoras, devemos lidar com as experiências imagéticas na contemporaneidade? Questionadas sobre como as imagens estiveram presentes nas formações pessoais e que influenciaram na escolha pela graduação, foi possível observar o seguinte relato:

Sempre gostei de filmes históricos com foco na Segunda Guerra Mundial, na leitura também segui este mesmo caminho... Em relação aos videogames "Assassins Creed" que remete à histórias antigas, desde Roma Antiga até Guerra Civil. (Questionário 17).

O que filmes e games têm a ver com a constituição de gostos por determinadas temáticas e disciplinas? Podemos arriscar que eles contribuem para algo importante no ensino de História, que é facilitar o trabalho com a imaginação que os conteúdos históricos constroem. Como diz a aluna, o videogame remete à história.... Ela acaba fazendo uma relação imediata entre o que vê no videogame e a "verdade" histórica, sem problematizar que essa forma de produção é uma leitura da história e não "a" História. Quando filmes e videogame são trazidos para a escola sem a problematização das construções desses artefatos culturais, eles adquirem o status de "verdade". A organização das escolas em horários fechados dificulta um trabalho imediatamente após a exibição de algum filme, dando-Ihe um caráter de verdade, não de construção. Fica o filme pelo filme.

Existe uma multiplicidade de possibilidades de ver e ser visto, possibilidades estas que chegam às escolas. Colocar essa vulnerabilidade e diversidade de experiências com as imagens em discussão na formação em Pedagogia é pensar que modelos de escolas, professores e relação ensino-aprendizagem queremos vivenciar. Mais do que isso é evidenciar que elas também dizem de algo que está não somente nas escolas, mas na nossa sociedade que é a multiplicidade de sentidos, significados, usos que fazemos das e com as imagens e que dizem das nossas experiências, contextos, formação, subjetividades, afetividades e até mesmo delírios. Fabiana de Amorim Marcello (2009) 
"Não me lembro, não me recordo..." Experiências com cultura visual antes da Graduação em Pedagogia.

discute sobre a necessidade de a escola ultrapassar a tendência conservadora de classificar as produções existentes na vida social. No momento em que a escola reconhecer suas próprias potencialidades, possivelmente caminhará rumo ao entendimento de que há necessidade de

romper com certo "didatismo" quando o assunto é arte ou mesmo imagem: ver, naquela tela, naquela instalação, o que o artista quis "mesmo" dizer; entender o que aquela imagem "representa" ou quer "representar". Uma possibilidade instigante poderia ser a de enfatizar perspectivas de trabalho que fossem além daquelas ligadas às "significações corretas", aos "ensinamentos", às "mensagens". [...] Ou seja, de considerar as infinitas possibilidades de olhar para além da conexão entre imagens e palavras. Quando falamos de imagens (e de arte) não há "ensinamentos" previsíveis, no sentido de que não há interferências possíveis naquilo que diz respeito à fruição, ao deleite, à sensibilidade: pode-se até obrigar alguém a aprender algo, mas não se pode ensinar alguém a se emocionar. (MARCELLO, 2009, p. 157-8).

Quando, ao longo deste texto, viemos discutindo sobre a presença das imagens na vida escolar das graduandas em Pedagogia, de certa maneira, viemos refletindo também sobre práticas pedagógicas de professores que, em maior ou menor quantidade, possibilitaram experiências dessa natureza. Isso nos faz pensar sobre a formação docente, tanto a inicial quanto também a formação em serviço, denominada também de formação continuada. As falas das alunas foram bastante reveladoras nesse sentido. Não pretendemos encerrar aqui as discussões que essa pesquisa nos possibilitou, ao contrário disso, pensamos ser importante permanecer com as indagações em aberto. Trazer à tona questões que despertem, principalmente, para a necessidade de um olhar sensível para a docência que se inicia na vida das graduandas talvez seja uma perspectiva a se considerar. Na necessidade de, por ora, finalizar este texto, nós nos remeteremos ao que nos diz Luciana Loponte (2008) acerca dessa discussão:

Se a docência se alimenta pouco da arte contemporânea ou da arte em geral para pensar e problematizar o tempo que vivemos, 
se a escola ainda é o reino das imagens e fórmulas repetidas, dos estereótipos e binarismos que se tornam verdade quase inquestionáveis, há com certeza, muito que fazer, pensar, propor para a formação docente. Uma das questões é, sem dúvida, introduzir essas discussões de forma contundente nos cursos de licenciatura de todas as áreas de conhecimento (LOPONTE, 2008, p. 161).

Nessa pesquisa sobre a cultura visual para alunas do curso de Pedagogia, acabamos concentrando atenção nas experiências visuais, algo que é muito comum quando olhamos para os trabalhos com cultura visual que estão preocupados com os fenômenos visuais que estão acontecendo atualmente na utilização social, afetiva e políticopedagógica das imagens. Que práticas pedagógicas emergem destes usos com e das imagens?

Como defende Loponte (2008) na citação acima, nosso investimento é o mesmo que organiza as produções em torno da cultura visual e seu poder educativo, ou seja, introduzir uma discussão que seja capaz de colocar sob suspeita nossas formações, nossas formas de pensar e agir vinculadas aos usos e experiências com as imagens. Para nós, o trabalho com as imagens é o resultado de interpretação, que é, ao final, prática de produção de significados. Afirmar não apenas que o trabalho com as imagens é uma possibilidade de produção de significados, mas também ressaltar que ela passa pelo ponto de vista do observador/espectador em termos de gênero, classe, raça, faixa etária e demais experiências que constituem esses sujeitos que estão em negociação nas práticas de ver e de serem vistos.

\section{Considerações Finais}

Ao longo deste texto, buscamos refletir sobre as experiências com imagens que as alunas do curso de Pedagogia da Universidade Federal de Juiz de Fora tiveram antes de ingressarem na graduação. A ênfase nas perguntas centrou-se, principalmente, na utilização de imagens na disciplina História. Com isso, analisamos suas respostas dadas ao questionário qualitativo, em que as alunas puderam voltaram seu olhar para o que viveram no Ensino Fundamental e Médio. Questões importantes acerca da cultura visual foram suscitadas a partir das respostas das alunas e suscitaram reflexões importantes, principalmente no que tange à formação de professores.

Revista Digital do LAV - Santa Maria - vol. 10, n. 1, p. 82 - 98 - jan./abril. 2017 ISSN 19837348

http://dx.doi.org/10.5902/1983734826286 
"Não me lembro, não me recordo..." Experiências com cultura visual antes da Graduação em Pedagogia.

As alunas que participaram da pesquisa estão finalizando sua graduação, portanto, cabe ressaltar que a maioria delas terminou o Ensino Médio na última década. Assim, suas experiências na Educação Básica não traduzem realidades muito distantes dos dias em que vivenciamos hoje. Dessa forma, coube a nós tentar refletir e compreender como a escola vem se utilizando das imagens em suas práticas pedagógicas, como a produção das imagens vem tendo destaque frente a uma realidade extremamente visual a que estamos expostos no nosso dia a dia.

A pesquisa nos indicou que as imagens vêm sendo trabalhadas na forma de ilustração e muito pouco como produção. Isso nos levou a refletir que as imagens podem estar sendo consideradas como algo secundário, no momento de definição de estratégias metodológicas eleitas pelos educadores e educadoras. Pelas falas das alunas, foi possível perceber que, quando o trabalho com imagens acontecia em sala de aula, o destaque dado por elas ressaltava a relevância da iniciativa.

\section{Referências}

BARBOSA, Ana Mae. O ensino da arte e do design quando se chamava desenho: reforma Fernando de Azevedo. In. FERRARI, Anderson. Dossiê Cultura Visual e Educação. Revista Educação em Foco, vol. 18, n.2, Juiz de Fora: EdUFJF, 2013.

Tópicos Utópicos. Belo Horizonte: C/Arte, 1998.

BREA, José Luis. Estudios Visuales: La epistemología de la visualidad en la era de la globalización. Madrid: Ediciones Akal, 2005.

FORQUIN, Jean Claude. Escola e Cultura: as bases sociais e epistemológicas do conhecimento escolar. Porto Alegre: Artmed, 1993.

- Evoluções recentes do debate sobre a escola, a cultura e as desigualdades na França. In. FRANCO, C. (org.). Avaliação, ciclos e promoção na educação. Porto Alegre: Artmed, 2001.

HERNÁNDEZ, Fernando. Cultura visual, mudança educativa e projeto de trabalho. Porto Alegre: Artmed, 2000.

Catadores da Cultura Visual: transformando fragmentos em nova narrativa educacional. Porto Alegre: Mediação, 2007.

Revista Digital do LAV - Santa Maria - vol. 10, n. 1, p. 82 - 98 - jan./abril. 2017 ISSN 19837348

http://dx.doi.org/10.5902/1983734826286 
Educación y Cultura Visual. Barcelona: Octaedro, 2010.

JENKINS, Keith. A História repensada. São Paulo: Contexto, 2011.

LOPONTE, Luciana Grupelli. Pedagogias visuais do feminino: arte, imagens e docência. Currículo sem fronteiras, v.08, n.2, pp. 148-164, Jul/Dez 2008. Disponível em www.curriculosemfronteiras.org. Acesso em: abril de 2015.

MARCELLO, Fabiana de Amorim. Cinema e Pedagogia do olhar. In: COSTA, Marisa Vorraber (org.). A educação na cultura da mídia e do consumo. Rio de Janeiro: Lamparina Editora, 2009.

MARSHALL, J. Michel Foucault: pesquisa educacional como problematização. In: PETERS, M.A.; BESLEY, T. (orgs). Por que Foucault? Novas diretrizes para a pesquisa educacional. Porto Alegre: Artmed, 2008.

MARTINS, Raimundo. Narrativas Visuais: imagens, visualidades e Experiência educativa. VIS - Revista do Programa de Pós-Graduação em Arte da UNB. Vol.8, n.1, 2009.

NÓVOA, Antônio. Os professores e as histórias de sua vida. In: (org.). Vida de professores. 2a. Ed. Porto: Porto Editora, 1995.

OLIVEIRA, Marilda Oliveira de. Três notas sobre a formação inicial em Artes Visuais: a perspectiva da cultura visual, o endereçamento e os diários de aula. In; FERRARI, Anderson. Dossiê Arte, Cultura Visual e Educação. Instrumento Revista de estudo e pesquisa em educação, vol. 14, n. 2, Juiz de Fora: EdUFJF, 2012.

SILVA, Tomaz Tadeu da. Documentos de identidade: uma introdução às teorias do currículo. Belo Horizonte: Autêntica, 1999. 156 p.

TARDIF. M. Saberes docentes \& Formação profissional. Petrópolis: Vozes, 2002.

TOURINHO, Irene; MARTINS, Raimundo; MARTINS, Alice Fátima. Entre subjetividades e aparatos pedagógicos: o que nos move a aprender? Visualidades: Revista do Programa de Mestrado em Cultura Visual. Goiânia:UFG, FAV, 2013, p. 59-72.

WALTER, John A. \& CHAPLIN, Sarah. Uma introduccióna La Cultura visual. Barcelona: Ediciones Octaedro, 2002.

Revista Digital do LAV - Santa Maria - vol. 10, n. 1, p. 82 - 98 - jan./abril. 2017 ISSN 19837348

http://dx.doi.org/10.5902/1983734826286 
"Não me lembro, não me recordo..." Experiências com cultura visual antes da Graduação em Pedagogia.

ii Doutoranda em Educação pelo PPGE/UFJF, possui Mestrado em Educação (2006), Especialização em Linguagem (1997) e Formação inicial em Pedagogia (1995), todos pela Universidade Federal de Juiz de Fora. Atualmente é Coordenadora Pedagógica e Professora da Rede Municipal de Juiz de Fora. Tem experiência na área de Educação Básica, com ênfase em Educação Infantil, atuando principalmente nos seguintes temas: políticas públicas, educação infantil, educação básica, cultura, conhecimento, linguagem. Participa do Grupo de Estudos e Pesquisas em Gênero, Sexualidade, Educação e Diversidade da Faculdade de Educação da UFJF.

\footnotetext{
ii Possui graduação em Licenciatura Em História pela Universidade do Estado do Rio de Janeiro (1991), graduação em Bacharelado em História pela Universidade do Estado do Rio de Janeiro (1994), mestrado em Educação pela Universidade Federal de Juiz de Fora (2000) e doutorado em Educação pela Universidade Estadual de Campinas (2005). Atualmente é professor adjunto de Ensino de História da Faculdade de Educação da UFJF, lecionando as disciplinas de Prática Escolar, Fundamentos Teóricometodológico em História e Didática e Prática do Ensino de História. É professor permanente do PPGE/UFJF (mestrado e doutorado) da Universidade Federal de Juiz de Fora. Tem experiência na área de Educação, com ênfase em Linguagem Conhecimento e Formação de Professores, atuando principalmente nos seguintes temas: educação, gênero, sexualidade, currículo e homossexualidade. Em 2010 desenvolveu o período de pós doutorado na Faculdade de Belas Artes da Universidade de Barcelona, trabalhando com a relação entre Cultura Visual, Educação e Homossexualidades. Em 2013 foi agraciado com a menção honrosa Cora Coralina do edital da ANPED/SECADI pela importante contribuição para área de Diversidade Sexual e Educação. Entre 2014 a 2016 ocupou o cargo de presidente nacional da ABEHAssociação Brasileira de Estudos da Homocultura.
}

Enviado em: 23 de março de 2017.

Aprovado em: 28 de abril de 2017

Revista Digital do LAV - Santa Maria - vol. 10, n. 1, p. 82 - 98 - jan./abril. 2017 ISSN 19837348

http://dx.doi.org/10.5902/1983734826286 